\title{
Solvent Extraction and Stripping of Gold(III) from Hydrochloric Acid Solution Using Vacuum Pump Oil
}

\author{
Ying XIONG ${ }^{1,2}$, Hidetaka KAWAKITA ${ }^{1}$, Jun-ichi INOUE ${ }^{1}$, Minoru ABE ${ }^{1}$, Keisuke OHTO ${ }^{1}$, \\ Katsutoshi INOUE ${ }^{1 *}$, and Hiroyuki HARADA ${ }^{1}$ \\ ${ }^{1}$ Department of Applied Chemistry, Saga University, 1-Honjo, Saga 840-8502, Japan \\ ${ }^{2}$ College of Chemistry, Liaoning University, Shenyang 110036, China \\ (Received December 23, 2009; Accepted February 12, 2010)
}

\begin{abstract}
Vacuum pump oil (VPO) in toluene was employed as a solvent extraction reagent for $\mathrm{Au}(\mathrm{III})$ from $\mathrm{HCl}$. The effects of shaking time and concentration of $\mathrm{HCl}$ on the extraction of $\mathrm{Au}(\mathrm{III})$ were investigated. It was found that the selectivity of VPO for $\mathrm{Au}(\mathrm{III})$ was superior even to dibutylcarbitol (DBC) which is currently employed as a commercial extactant for gold. The extraction of Au(III) with VPO is nearly quantitative over the whole $\mathrm{HCl}$ concentration range, while the extraction of other metal ions is nearly negligible. In addition, in case of the VPO system, the extraction of $\mathrm{Au}$ (III) was independent of $\mathrm{HCl}$ concentration regardless of the VPO concentration, while in the case of $\mathrm{DBC}$, it is independent of $\mathrm{HCl}$ concentration only for $100 \% \mathrm{DBC}$. The loading capacity for $\mathrm{Au}(\mathrm{III})$ was compared between $10 \% \mathrm{VPO}$ in toluene and $100 \% \mathrm{DBC}$. The stripping of $\mathrm{Au}(\mathrm{III})$ from the loaded VPO was also investigated using aqueous mixtures of thiourea and hydrazine in combination with varying concentrations of $\mathrm{HCl}$ and $\mathrm{NaOH}$. It was found that complete stripping can be achieved by these combinations and that gold is recovered as solid particles in some cases.
\end{abstract}

\section{Introduction}

Nowadays gold is in extensive use not only for traditional use in jewelry but also for the production of various advanced materials like electric and electronics devices as well as gold nano-particles for medical use. For example, it is well known that mobile phones contain gold 
the content of which is more than 10 times greater than that of common gold ores. Consequently, it is of prime importance to recycle gold from various gold-containing wastes, in particular from small size domestic electronics like mobile phones, digital camera and so on.

Solvent extraction is a very effective method for the separation and recovery of precious metals [1,2]. Many types of extractants have been reported for gold, such as reagents containing oxygen or sulfur as donor atoms, and quaternary ammonium compounds as well as phosphorus compounds [3-13]. Among them, dibutylcarbitol (DBC) has been commercially employed as a reagent for gold(III) from acidic chloride media in some commercial plants $[14,15]$. In the process operated in Inco's Acton precious metal refinery, gold is recovered by solvent extraction with undiluted DBC after the recovery of ruthenium and osmium by distillation from the liquor from an $\mathrm{HCl}$ total leach of anode slimes of copper or nickel [15]. In this step, gold is highly selectively recovered over palladium, platinum, iridium, rhodium and base metals. Loaded gold in DBC is then reductively stripped as particles of metallic gold with aqueous oxalic acid solution [14].

However, the selectivity of DBC for gold is not always satisfactory and also the solvent loss into the aqueous phase should be taken into consideration. For these reasons, some new solvent extraction reagents for gold have been developed as well as new stripping methods [16-18]. Narita et al. developed two new amide-type reagents: $N, N$-di-n-octylacetamide (DOAA) and $N, N$-di-n-octylauramide (DOLA). Both DOAA and DOLA exhibited high selectivity for gold over a wide range of $\mathrm{HCl}$ concentrations $(0.1-4 \mathrm{M})$ and a high loading capacity for gold [17]. However, stripping of gold from the organic to the aqueous phase was not complete. Stripping using water transfers only $15 \%$ of gold from the organic loaded with $1-20 \mathrm{~g} / \mathrm{L} \mathrm{Au}$ to the aqueous phase in the case of DOAA, and $40-70 \%$ in the case of DOLA. On the other hand, using a mixture of thiourea and $\mathrm{HCl}, 70-100 \%$ of the loaded gold was stripped under the same conditions. However, a gold-thiourea complex precipitate formed in the organic phases containing $20 \mathrm{~g} / \mathrm{L} \mathrm{Au}$, rendering this technique ineffective for practical application. Recently, a novel stripping method was reported in which gold was recovered as solid fulminating gold $\mathrm{Au}_{2} \mathrm{O}_{3} \times 3 \mathrm{NH}_{3}$, which was formed from the direct reaction between concentrated ammonia and the gold in the DBC. This intermediate product was then further reduced to metallic gold powder by hydrazine [18]. 
Because it is costly to develop novel solvent extraction reagents for commercial scale operation even if these new reagents exhibit remarkably excellent extraction behavior, the chemical companies that produce solvent extraction reagents are unwilling to develop new reagents. It would be fortuitous if some cheap water insoluble organic chemicals used for large scale purposes other than solvent extraction can be employed as solvent extraction reagents. In the present paper, based on this concept vacuum pump oil (VPO) has been employed as the solvent extraction reagent for gold from $\mathrm{HCl}$ and the stripping method for the gold from the loaded VPO has also been studied.

\section{Experimental}

\subsection{Materials.}

Dibutyl carbitol (abbreviated as DBC, hereafter) with a purity greater than $99 \%$ was purchased from Tokyo Kasei Kogyo Co. Ltd, Japan, and used without dilution. Vacuum pump oil (NEOVAC MR-200, MORESCO Corporation, abbreviated as VPO, hereafter), as the extractant, was used without any further purification, and diluted in reagent grade toluene to the required concentration because it is difficult to use it undiluted because of its high viscosity.

Analytical grade chloride salts of copper, iron, palladium, nickel and zinc were used to prepare test solutions of the respective metals. Analytical grade $\mathrm{HAuCl}_{4} \cdot 4 \mathrm{H}_{2} \mathrm{O}$ and $\mathrm{H}_{2} \mathrm{PtCl}_{6} \cdot 6 \mathrm{H}_{2} \mathrm{O}$ were used to prepare gold and platinum solutions, respectively. All other reagents were of analytical grade or higher.

\subsection{Methods.}

In the equilibrium extraction experiments, aqueous and organic phases were shaken in a thermostated water bath maintained at $303 \mathrm{~K}$ for $98 \mathrm{~h}$, which was confirmed to be sufficient to attain equilibrium in preliminary experiments. Equal volumes $(10 \mathrm{~mL}$ each) of aqueous and organic phases were shaken in all equilibrium extraction experiments except for the loading test with undiluted $\mathrm{DBC}$, in which the two phases were shaken at an $\mathrm{O} / \mathrm{A}$ ratio $=10$. After phase separation, the concentration of metal ions in the aqueous phase was measured by using a Shimadzu model AA-6650 atomic absorption spectrophotometer and that in the organic phase was calculated by material balance. 
In the stripping experiments, the loaded organic phase was prepared by shaking the organic solution of $10 \% \mathrm{VPO}$ in toluene with the aqueous phase containing $1 \mathrm{mM} \mathrm{Au}(\mathrm{III})$. From the loaded organic phase, $\mathrm{Au}(\mathrm{III})$ was stripped using aqueous mixtures of thiourea or hydrazine with varying concentrations of $\mathrm{HCl}$ or $\mathrm{NaOH}$ by shaking both phases at $303 \mathrm{~K}$ for $98 \mathrm{~h}$. As will be reported later, stripping sometimes resulted in the formation of aggregates of fine solid particles. In such cases, the aggregates were separated by filtration and the filter cake was examined by using a KEYENCE model VHX/VH digital microscope.

\section{Results and Discussion}

\subsection{Effect of shaking time on the extraction of Au(III)}

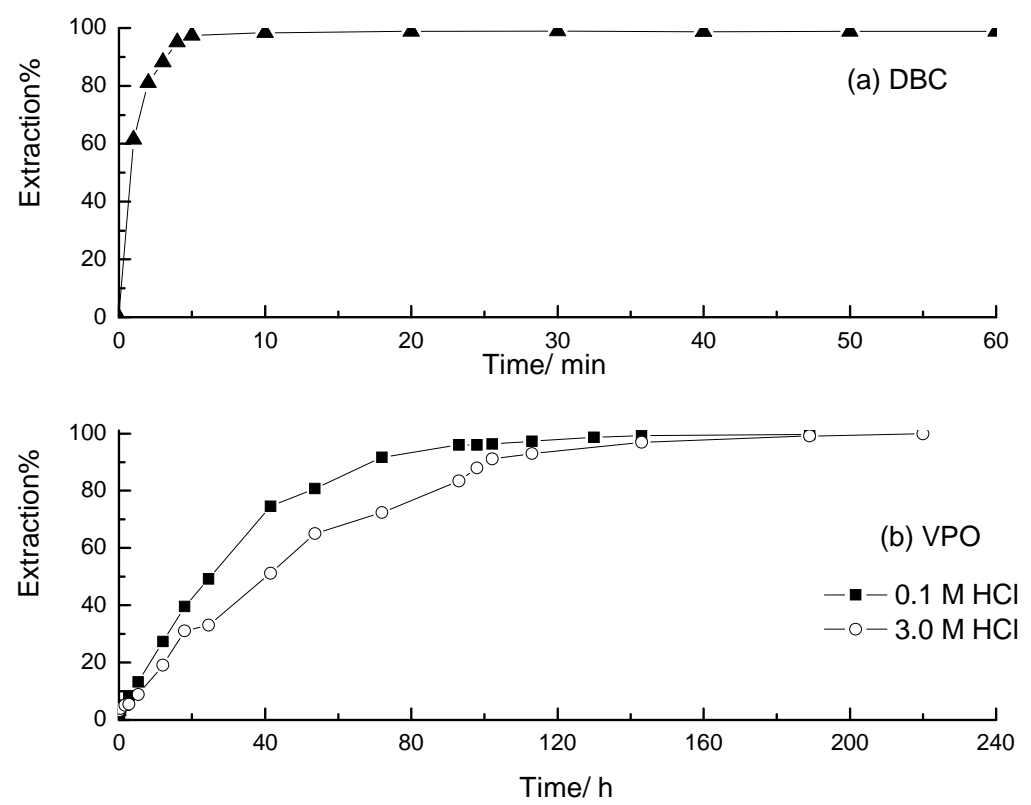

Figure 1. Extraction \% of $\mathrm{Au}(\mathrm{III})$ with (a) $100 \% \mathrm{DBC}$ and (b) $10 \% \mathrm{VPO}$ as a function of shaking time. $[\mathrm{HCl}]=3.0 \mathrm{M}$, temperature $=303 \mathrm{~K}$. (a) $[\mathrm{Au}(\mathrm{III})]=40 \mathrm{mM}, \mathrm{O} / \mathrm{A}=10$. (b) $[\mathrm{Au}(\mathrm{III})]=1 \mathrm{mM}, \mathrm{O} / \mathrm{A}=1$.

Figure 1 (a) and (b) show the extraction \% of $\mathrm{Au}(\mathrm{III})$ with undiluted DBC and VPO in toluene, respectively, as a function of the shaking time at $303 \mathrm{~K}$. It is seen from these figures that equilibrium is rapidly attained in the case of the DBC system, whereas, in the case of VPO, equilibrium is reached after about $90 \mathrm{~h}$, indicating that the extraction kinetics in the 
VPO system are much slower than that in the DBC system. Hence, in subsequent experiments, the test samples were shaken for longer than at least $98 \mathrm{~h}$.

Figure 2 shows the pseudo-first order reaction plot of the kinetic data. All points fall on straight lines as expected from the pseudo-first order kinetics. From the slopes of these straight lines, the rate constants were evaluated as $0.034 \mathrm{~h}^{-1}$ for $0.1 \mathrm{M} \mathrm{HCl}$ and $0.024 \mathrm{~h}^{-1}$ for 3.0 $\mathrm{M} \mathrm{HCl}$ in the case of the VPO system, compared to $43 \mathrm{~h}^{-1}$ in the case of the DBC system. It is obvious that the extraction rate of $\mathrm{Au}(\mathrm{III})$ with $\mathrm{DBC}$ is about 1500 times faster than that with the VPO system.
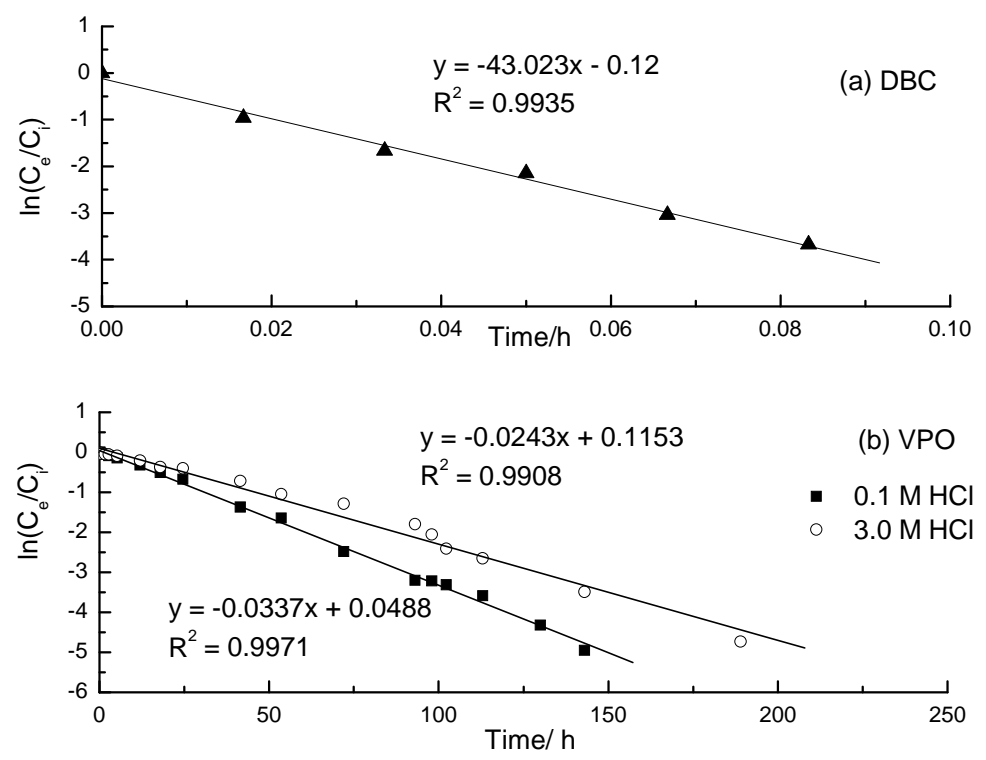

Figure 2. Plots of the kinetic data for the extraction of $\mathrm{Au}(\mathrm{III})$ with (a) $100 \% \mathrm{DBC}$ and (b) $10 \% \mathrm{VPO}$ in toluene based on the pseudo-first order kinetic equation. $[\mathrm{HCl}]=3.0 \mathrm{M}$, temperature $=303 \mathrm{~K}$. (a) $[\mathrm{Au}(\mathrm{III})]=40 \mathrm{mM}, \mathrm{O} / \mathrm{A}=10$. (b) $[\mathrm{Au}(\mathrm{III})]=1 \mathrm{mM}, \mathrm{O} / \mathrm{A}=1$.

\subsection{Effect of $\mathrm{HCl}$ concentration on the equilibrium extraction of Au(III)}

Figure 3(a) shows the dependence of the extraction \% of various metal ions including $\mathrm{Au}(\mathrm{III})$ with undiluted $\mathrm{DBC}$ on the $\mathrm{HCl}$ concentration. The extraction \% of $\mathrm{Au}(\mathrm{III})$ is slightly decreased at low $\mathrm{HCl}$ concentrations, while at high concentrations, extraction of $\mathrm{Fe}(\mathrm{III})$ significantly increases with increasing $\mathrm{HCl}$ concentration. Figure 3 (b) shows similar plots for extraction with $10 \% \mathrm{VPO}$ in toluene. Contrary to DBC, the extraction of $\mathrm{Au}(\mathrm{III})$ is nearly quantitative over the whole $\mathrm{HCl}$ concentration range, while other metal ions are barely 
extracted in this concentration range. This result indicates that $\mathrm{Au}(\mathrm{III})$ can be more selectively extracted with VPO than DBC over any other coexisting base metals and precious metal ions in hydrochloric acid medium.
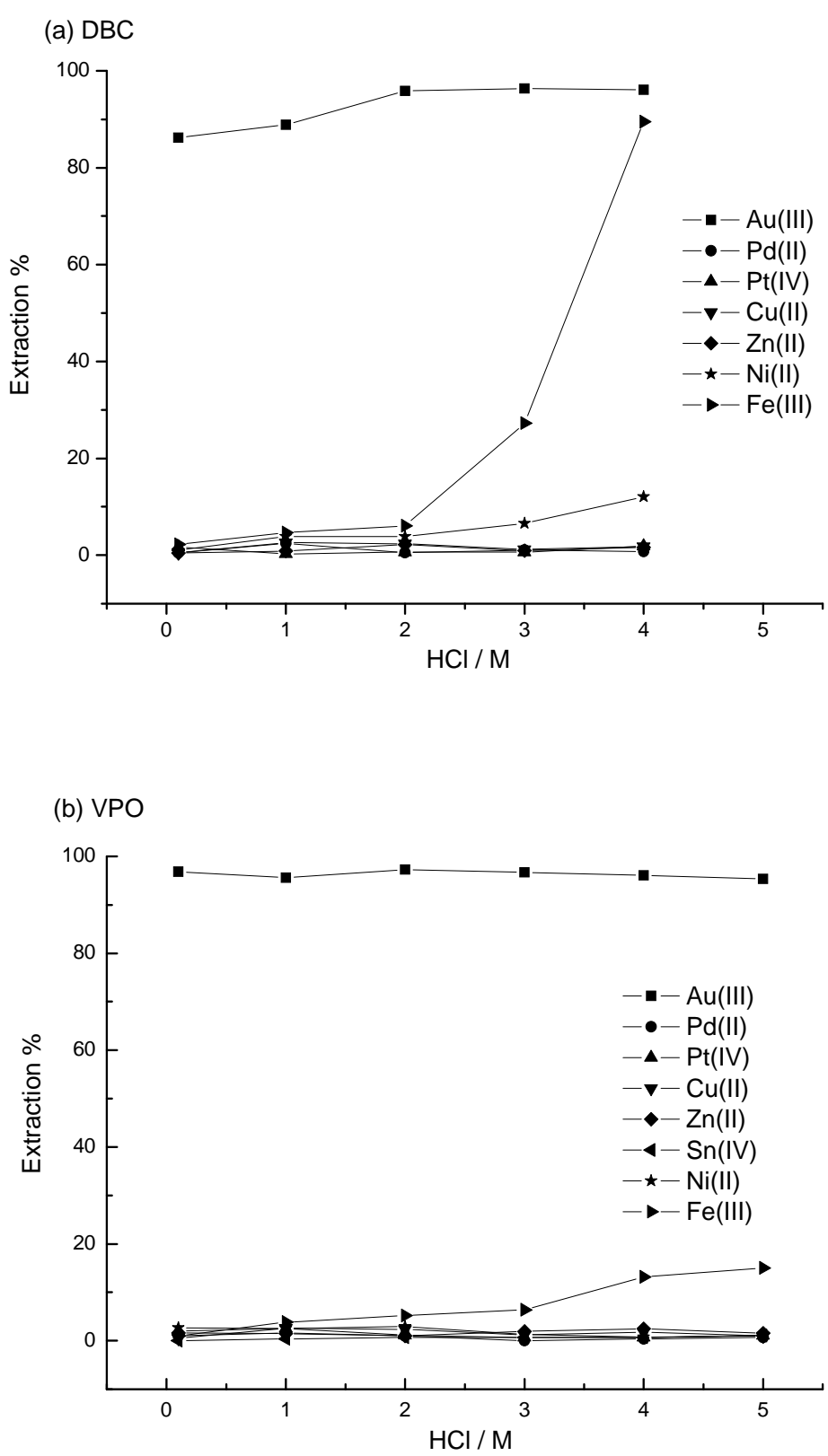

Figure 3. Extraction \% of some precious and base metals with (a) $100 \%$ DBC and (b) $10 \%$ VPO in toluene as a function of $\mathrm{HCl}$ concentration. Concentration of metal ions $=0.2 \mathrm{mM}$, Shaking time $=98 \mathrm{~h}, \mathrm{O} / \mathrm{A}=1$, temperature $=303 \mathrm{~K}$. 
Figure 4 shows the effect of $\mathrm{HCl}$ concentration on the extraction $\%$ of $\mathrm{Au}(\mathrm{III})$ at different extractant concentrations for VPO and DBC. It is clear that the extraction \% of $\mathrm{Au}(\mathrm{III})$ is independent of the $\mathrm{HCl}$ concentration even at different extractant concentrations in the VPO system. On the other hand, for the DBC system, the extraction of $\mathrm{Au}(\mathrm{III})$ with $50 \%$ $\mathrm{DBC}$ in toluene is quite low at low $\mathrm{HCl}$ concentrations while it gradually increases with increasing $\mathrm{HCl}$ concentration. Thus, this is considered to be the reason why pure DBC is commercially employed without dilution.
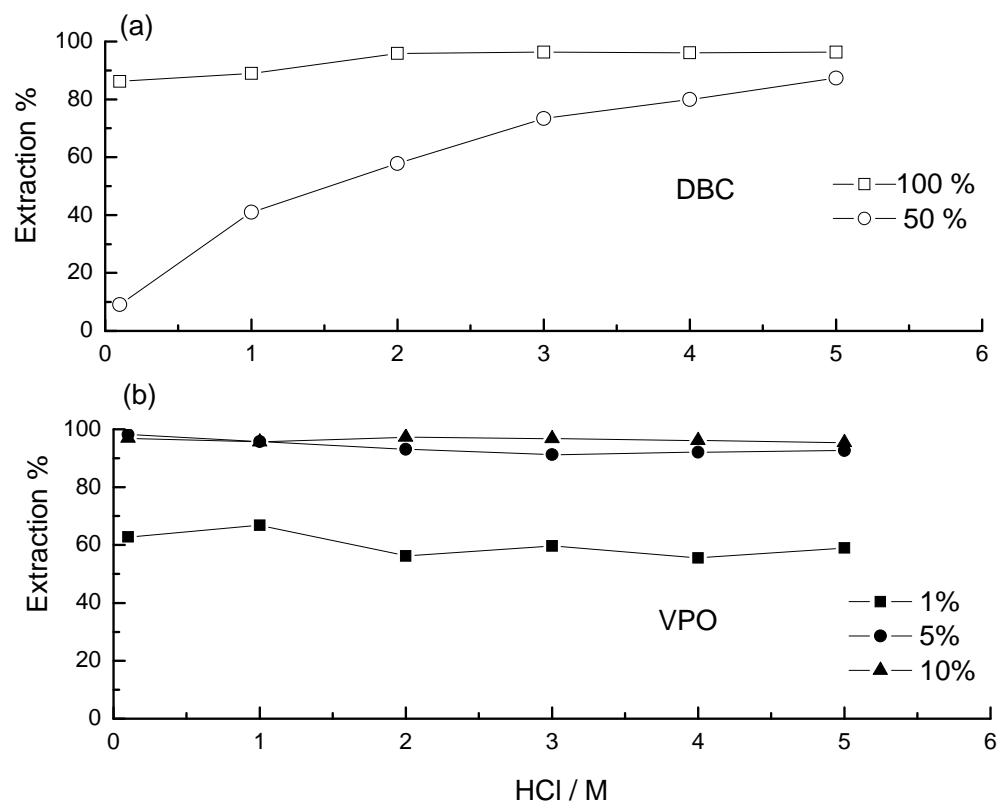

Figure 4. Extraction \% of $\mathrm{Au}(\mathrm{III})$ with different concentrations of (a) DBC and (b) VPO in toluene as a function of $\mathrm{HCl}$ concentration. $[\mathrm{Au}(\mathrm{III})]=0.2 \mathrm{mM}$, Shaking time $=98 \mathrm{~h}, \mathrm{O} / \mathrm{A}=1$, temperature $=303 \mathrm{~K}$.

\subsection{Loading test of Au(III)}

Figure 5 (a) and (b) illustrate the plots of the amount of Au(III) extracted against $\mathrm{Au}(\mathrm{III})$ concentration in the aqueous phase at equilibrium, i.e. the extraction isotherms for $\mathrm{Au}(\mathrm{III})$, in the extraction from $3 \mathrm{M} \mathrm{HCl}$ with undiluted $\mathrm{DBC}$ and $10 \% \mathrm{VPO}$ in toluene, respectively. In both cases, the amount of $\mathrm{Au}(\mathrm{III})$ extracted increases with increasing concentration in the low concentration range while it tends to approach a constant value corresponding to each case at high concentration, similar to the well-known Langmuir 
adsorption isotherm. From the constant value, the maximum loading capacity of $\mathrm{Au}(\mathrm{III})$ in the organic phase was evaluated as $176 \mathrm{mM}(34.7 \mathrm{~g} / \mathrm{L})$ for undiluted $\mathrm{DBC}$, while it was evaluated as $5.5 \mathrm{mM}(1.08 \mathrm{~g} / \mathrm{L})$ for $10 \% \mathrm{VPO}$ in toluene. From this value, the maximum loading capacity for undiluted VPO is calculated as $55 \mathrm{mM}$, which is still much lower than that of undiluted DBC.

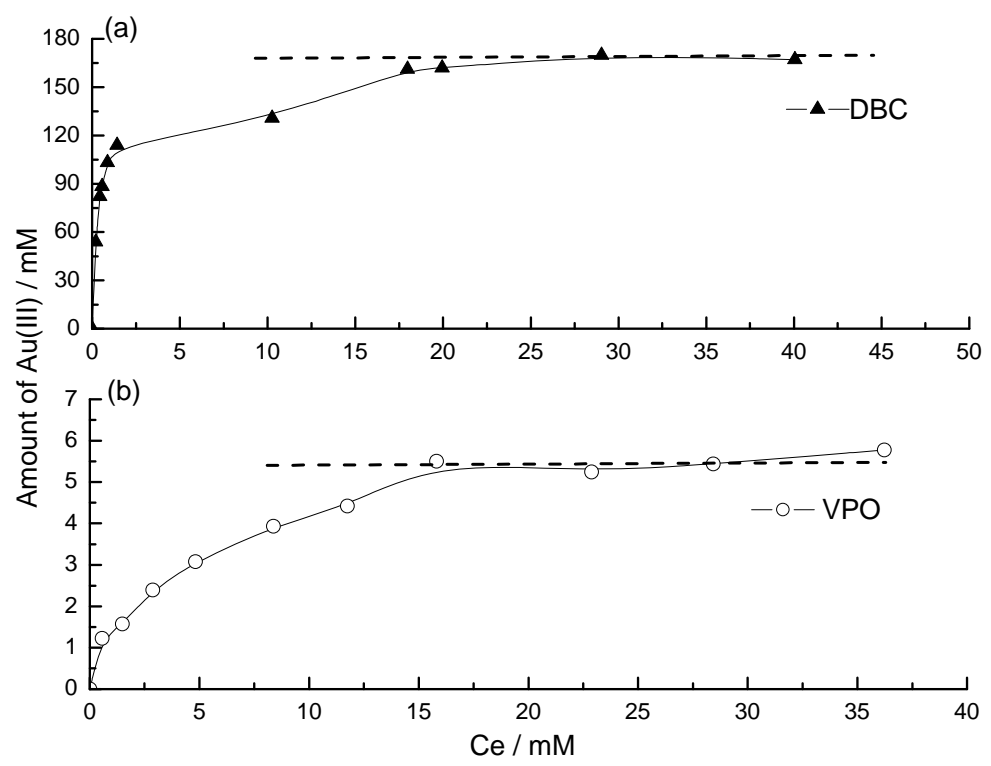

Figure 5. Relationship between the $\mathrm{Au}(\mathrm{III})$ concentrations in the organic and aqueous phases at equilibrium on extraction with (a) $100 \% \mathrm{DBC}$ and (b) $10 \% \mathrm{VPO}$ in toluene. $[\mathrm{HCl}]=3.0 \mathrm{M}$, Shaking time $=120 \mathrm{~h}$, temperature $=303 \mathrm{~K}$. (a) $\mathrm{O} / \mathrm{A}=10$. (b) $\mathrm{O} / \mathrm{A}=1$.

\subsection{Stoichiometric relationship in the extraction reaction of $\mathrm{Au}$ (III) with the active species in VPO}

In order to elucidate the stoichiometric relationship in the extraction reaction of $\mathrm{Au}(\mathrm{III})$ with the active species in VPO, the effect of VPO concentration on the distribution ratio of $\mathrm{Au}(\mathrm{III})$ was examined under conditions of constant $\mathrm{HCl}$ and $\mathrm{Au}(\mathrm{III})$ concentrations by means of conventional slope analysis as shown in Figure 6. As shown in this figure, the experimental data points are seen to lie on a straight line with a slope of about 1 for low concentrations of VPO while a slope of 2 appears at high concentrations, suggesting that $\mathrm{Au}(\mathrm{III})$ is extracted as 1:1 and 1:2 metal : reagent complexes at low and high VPO concentrations, respectively.

Thus at high VPO concentrations $([\mathrm{VPO}]>0.01 \mathrm{M})$ : 


$$
2 \mathrm{VPO}+\mathrm{HAuCl}_{4} \longleftrightarrow[\mathrm{VPO}]_{2} \cdot\left[\mathrm{HAuCl}_{4}\right]
$$

At low VPO concentrations $([\mathrm{VPO}] \leq 0.01 \mathrm{M})$ :

$$
\mathrm{VPO}+\mathrm{HAuCl}_{4} \longleftrightarrow[\mathrm{VPO}] \cdot\left[\mathrm{HAuCl}_{4}\right]
$$

In these equations, VPO stands for the active component in the extraction reaction with VPO.

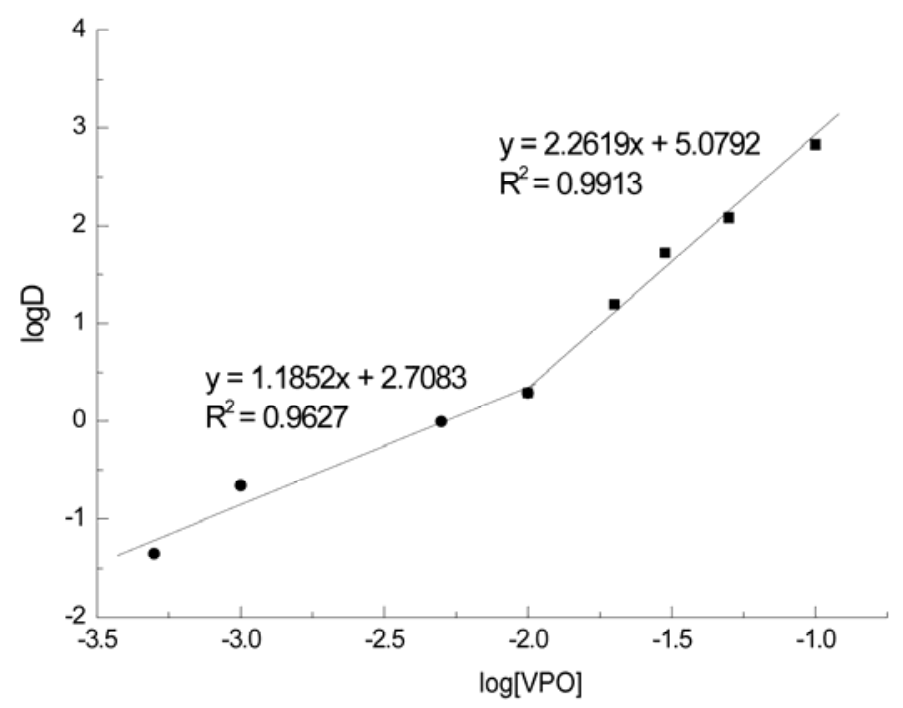

Figure 6. Relationship between the distribution ratio of $\mathrm{Au}(\mathrm{III}), \mathrm{D}$, and the equilibrium volume fraction of VPO. Initial concentration of $\mathrm{Au}(\mathrm{III})=0.2 \mathrm{mM}$, Shaking time $=98 \mathrm{~h}$, $\mathrm{O} / \mathrm{A}=1$, temperature $=303 \mathrm{~K}$

\subsection{Stripping of Au(III) from loaded VPO}

\subsubsection{Stripping with thiourea}

Figure 7 (a) shows the plot of the stripping $\%$ of Au(III) from the loaded $10 \%$ VPO in toluene containing $1 \mathrm{mM} \mathrm{Au}(\mathrm{III})$ with an aqueous mixture of thiourea together with varying concentrations of $\mathrm{HCl}$ or $\mathrm{NaOH}$. From this figure, it is seen that complete stripping of $\mathrm{Au}(\mathrm{III})$ can be achieved not only by the aqueous mixture of thiourea and $\mathrm{HCl}$ over the whole $\mathrm{HCl}$ concentration range but also by the mixture with relatively high concentrations of $\mathrm{NaOH}$. During stripping, the formation of solid fine particles was observed in the case of the thiourea- $\mathrm{NaOH}$ mixture as shown in the photograph in Figure 8 (a) taken by using a digital microscope. In this case, the majority of $\mathrm{Au}(\mathrm{III})$ was stripped as solid particles from the loaded VPO as shown in this figure. It is well known that, in acidic conditions, thiourea forms 
strong cationic complexes with gold(III), while, under basic conditions, it is unstable and readily decomposes to sodium sulfide. Thus, it is inferred that gold(III) is reduced to gold(I), and even to gold( 0 ) not directly by thiourea but by the aid of sodium sulfide.

\subsubsection{Stripping with hydrazine}

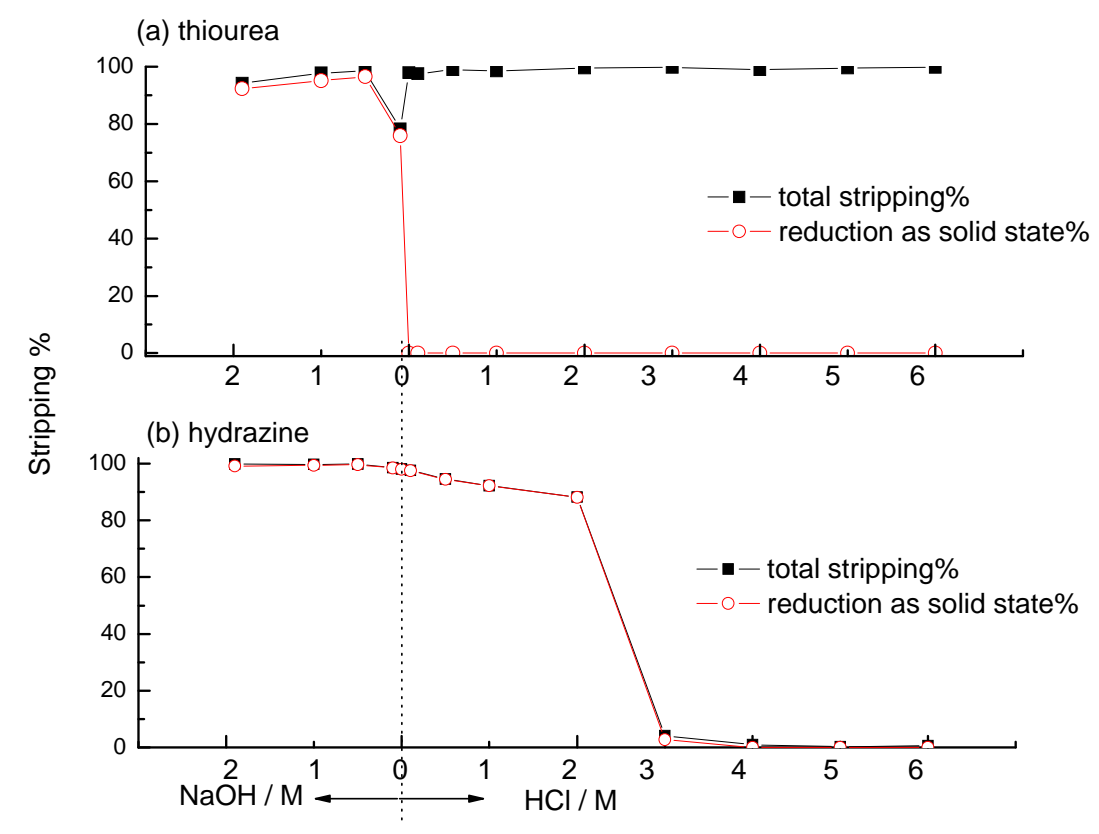

Figure 7. Stripping \% of $\mathrm{Au}(\mathrm{III})$ with aqueous mixtures of (a) thiourea and (b) hydrazine in combination with varying concentrations of $\mathrm{HCl}$, water and $\mathrm{NaOH}$. [Au(III)-loaded] $=1 \mathrm{mM}$, Shaking time $=98 \mathrm{~h}, \mathrm{O} / \mathrm{A}=1$, temperature $=303 \mathrm{~K}$.

In a similar manner to thiourea stripping, $10 \% \mathrm{VPO}$ in toluene loaded with $\mathrm{Au}(\mathrm{III})$ was back-extracted with aqueous mixtures of hydrazine with $\mathrm{HCl}$, water and $\mathrm{NaOH}$. The stripping behavior of $\mathrm{Au}(\mathrm{III})$ in this system was different from that observed in the thiourea system. Figure 7 (b) shows the stripping \% plot with aqueous mixtures of hydrazine together with varying concentrations of $\mathrm{HCl}$ and $\mathrm{NaOH}$. It was observed that the stripping \% of $\mathrm{Au}(\mathrm{III})$ increases with deceasing $\mathrm{HCl}$ concentration, and high stripping efficiency was achieved with the mixture of hydrazine with $\mathrm{NaOH}$ and with relatively low concentrations of $\mathrm{HCl}$ plus hydrazine. In this system, gold was stripped as solid fine particles not only by the mixture with $\mathrm{NaOH}$ but also by that with relatively low concentrations of $\mathrm{HCl}$ as shown in Figure 7(b). However, the morphology of the solid fine particle aggregates after filtration appears to be 
different between that stripped by the mixture with $\mathrm{HCl}$ and that with $\mathrm{NaOH}$ as shown in Figures 8 (b) and (c), respectively, suggesting that the chemical species of the solid particles may be different in these two cases.

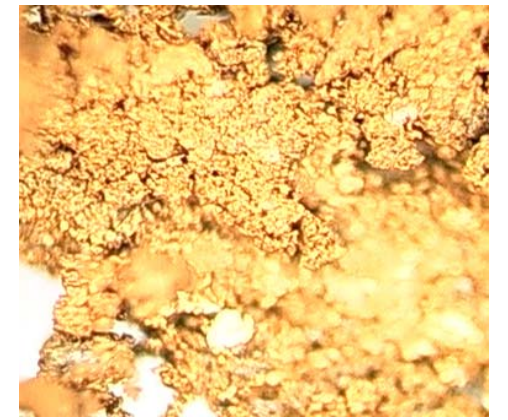

(a)

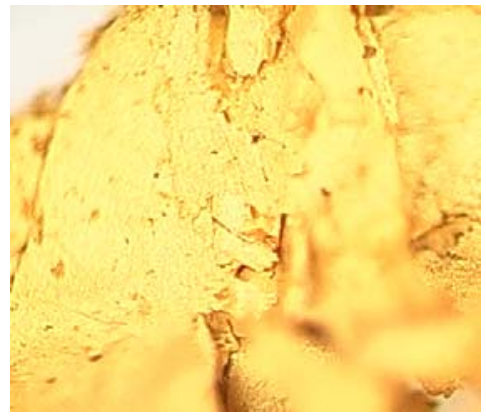

(b)

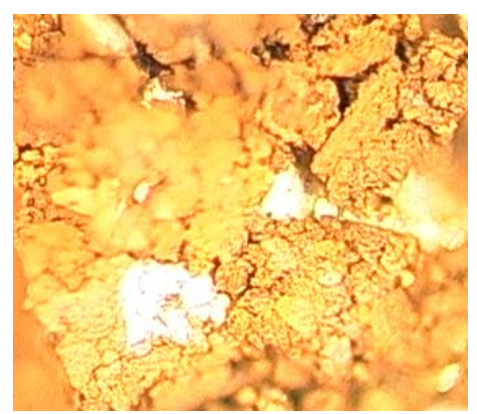

(c)

Figure 8. Images of digital micrographs of gold aggregates formed after stripping with (a) thiourea $-\mathrm{NaOH}$, (b) hyrazine- $\mathrm{HCl}$, (c) hyrazine- $\mathrm{NaOH}$.

\section{Conclusions}

The extraction of $\mathrm{Au}(\mathrm{III})$ from $\mathrm{HCl}$ has been studied using a VPO solution in toluene as the extraction solvent. Under the same conditions, it was compared with DBC which is commercially employed as a selective extractant for $\mathrm{Au}(\mathrm{III})$ from acidic chloride media. The experimental results suggested that the selectivity of VPO to $\mathrm{Au}(\mathrm{III})$ is superior to $\mathrm{DBC}$, and the extraction of $\mathrm{Au}(\mathrm{III})$ is independent of the $\mathrm{HCl}$ concentration regardless of the VPO concentration. Also, the stoichiometric relation of the extraction reaction was determined. Maximum loading capacity in $10 \%$ VPO in toluene was evaluated as $5.5 \mathrm{mM}(1.08 \mathrm{~g} / \mathrm{L})$. Moreover, Au(III) loaded in this solvent could be stripped by aqueous mixtures of thiourea and hydrazine with $\mathrm{HCl}$ or $\mathrm{NaOH}$. Further, it was found that the stripped gold formed aggregates of solid particles in all cases except for the case of the mixture of thiourea and $\mathrm{HCl}$. Compared with DBC, although VPO suffers from some drawbacks like slow extraction kinetics and low loading capacity, it may be considered to be commercially viable because of its higher selectivity for gold and because it is very cheap.

\section{Acknowledgements}

This study was financially supported by the Industrial Technology Research Grant 
Program in 2006 (06A18205c) from New Energy and Industrial Technology Development Organization (NEDO) in Japan.

\section{References}

1) M. Cox, "Solvent extraction in hydrometallurgy" in "Principles and Practices of Solvent Extraction", Eds. J. Rydberg, C. MUsikas, G. R Choopin, 1992, Macel Dekker, New York, pp. 357.

2) J. D. Edwards, te Riele, W. A. M., "Commercial processes for precious metals" in "Handbook of Solvent Extraction", Eds. T. C. Lo, M. H. I. Baird, C. Hanson, 1983, John Wiley and Sons, New York, pp. 725.

3) K. Liu, T. Y. Wan, A. Shibayama, T. Miyazaki, T. Fujita, Hydrometallurgy, 73, 41(2004).

4) D. F. C. Morris, M. A. Khan, Talanta, 15, 1301(1968).

5) H., Narita, M. Tanaka, K. Morisaku, T. Abe, Hydrometallurgy, 81, 153(2006).

6) N. R. Das, S. N. Bhattacharyya, Talanta, 23, 535(1976).

7) I M. Glesias, E. Antićo, V. Salvadó, Anal. Chim. Acta, 381, 61(1999).

8) N. H. Chung, M. Tabata, Talanta, 58, 927(2002).

9) L. Lin, T. J. Wen, F. Z. Liu, Journal of the Rare Metal Institute of China (in Chinese), 21, 179(1997).

10) W. T. Yen, K. Stogran, T. Fujita, Resources Treatment Technology (the Resource Processing Society of Japan), 43, 83(1996).

11) J. Zhao, Z. C. Wu, J. Y. Chen, Hydrometallurgy, 48, 133(1998b)

12) D. Zipperian, S. Raghavan, J. P. Wilson, Hydrometallurgy, 19, 361(1988).

13) M. E. Nunez, E. Rodr'1guez de San Miguel, F. Mercader-Trejo, J. C. Aguilar, J. de Gyves, Separ. Purif. Technol., 51, 57(2006).

14) B.F. Rimmer, Chem.Ind., 63 (1974)

15) J.E. Barnes, J.D. Edwards, Chem.Ind., 151 (1982)

16) Y. F. Shen, W. Y. Xue, Separation and Purification Technology, 56, 278(2007).

17) H. Narita, M. Tanaka, K. Morisaku, T. Abe, Hydrometallurgy, 81, 153(2006).

18) B. H. Jung, Y. Y. Park, J. W. An, S. J. Kim, T. Tran, M. J. Kim, Hydrometallurgy, 95, 262(2009). 